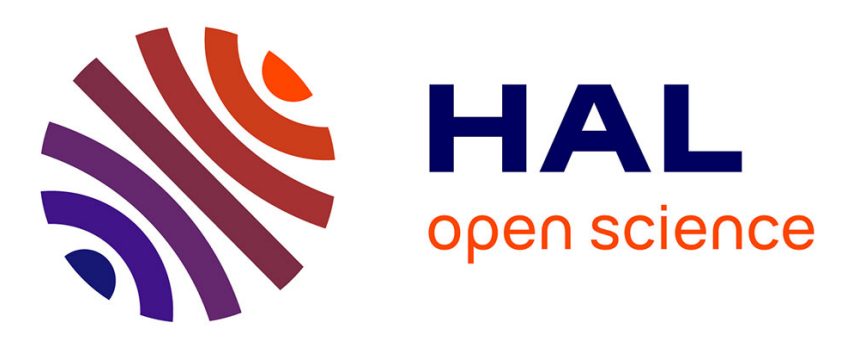

\title{
Real-time detection of lymphocytes binding on an antibody chip using SPR imaging.
}

Emmanuel Suraniti, Elodie Sollier, Roberto Calemczuk, Thierry Livache, Patrice Marche, Marie-Bernadette Villiers, Yoann Roupioz

\section{To cite this version:}

Emmanuel Suraniti, Elodie Sollier, Roberto Calemczuk, Thierry Livache, Patrice Marche, et al.. Realtime detection of lymphocytes binding on an antibody chip using SPR imaging.. Lab on a Chip, 2007, 7 (9), pp.1206-8. 10.1039/b708292d . inserm-00160965

\section{HAL Id: inserm-00160965 https://www.hal.inserm.fr/inserm-00160965}

Submitted on 1 Jul 2008

HAL is a multi-disciplinary open access archive for the deposit and dissemination of scientific research documents, whether they are published or not. The documents may come from teaching and research institutions in France or abroad, or from public or private research centers.
L'archive ouverte pluridisciplinaire HAL, est destinée au dépôt et à la diffusion de documents scientifiques de niveau recherche, publiés ou non, émanant des établissements d'enseignement et de recherche français ou étrangers, des laboratoires publics ou privés. 


\section{Real-time detection of lymphocytes binding on an antibody chip using SPR imaging}

Emmanuel Suraniti, ${ }^{a}$ Elodie Sollier, ${ }^{b}$ Roberto Calemczuk, ${ }^{a}$ Thierry Livache, ${ }^{a}$ Patrice N. Marche, ${ }^{b}$ Marie-Bernadette Villiers ${ }^{b}$ and Yoann Roupioz* ${ }^{a}$

${ }^{\text {a } C R E A B, ~ U M R} 5819$ (CNRS-CEA-UJF), CEA-Grenoble/DRFMC, 38054 Grenoble cedex 9, FRANCE.

Fax: +33 4387851 45; Tel: +33 4387898 79; E-mail: yoann.roupioz@cea.fr

${ }^{\mathrm{b}}$ INSERM U823, equipe 8, Institut Albert Bonniot, 38706 La tronche cedex , FRANCE 


\title{
Real-time detection of lymphocytes binding on an antibody chip using SPR imaging
}

\author{
Emmanuel Suraniti, ${ }^{a}$ Elodie Sollier, ${ }_{b}^{b}$ Roberto Calemczuk, ${ }^{a}$ Thierry Livache, ${ }^{a}$ Patrice N. \\ Marche, ${ }^{b}$ Marie-Bernadette Villiers ${ }^{b}$ and Yoann Roupioz ${ }^{* a}$
}

${ }^{\text {a }}$ CREAB, UMR 5819 (CNRS-CEA-UJF), CEA-Grenoble/DRFMC, 38054 Grenoble cedex 9, FRANCE. Fax: +33 4387851 45; Tel: +33 4387898 79; E-mail: yoann.roupioz@cea.fr

${ }^{\mathrm{b}}$ INSERM U823, equipe 8, Institut Albert Bonniot, 38706 La tronche cedex , FRANCE

We demonstrate the use of SPR imaging for detection of site-specific binding of either $B$ or $T$ lymphocyte populations on an electrochemically-grafted antibody array.

Biochips dedicated to cell analysis have generated tremendous interests in developing new tools for both diagnostic and research purposes. ${ }^{1}$ The goals sought after are based on rapid analysis, high ${ }_{15}$ throughput, small sample volumes and the use of biological compatible materials to increase detection efficiency. In the scope of functionalizing active surfaces toward biological samples, pyrrole coupling to biomolecules and subsequent electro-polymerization on a gold surface has been shown to be a versatile approach for designing biochips. ${ }^{2,3}$ Such electrochemically arrayed gold films can easily be coupled to Surface Plasmon Resonance (SPR) detection. This technique is a surface-sensitive method ${ }_{20}$ of increasing interest for bioanalysis as it allows label-free and real-time analysis of biomolecule interactions on functionalized surfaces. ${ }^{4}$ To design protein microarrays dedicated to cell sample analysis, we electrochemically arrayed thin gold layers with pyrrole-coupled antibodies. ${ }^{2}$ These conductive films are lying on glass prisms permitting SPR bioanalysis.

Blood contains a large number of different cell types, present at various concentrations. Red Blood ${ }_{25}$ Cells (RBC) constitute about 95\% of the blood cells, whereas platelets and leucocytes are present at much lower levels (about 4-6\% and 0.1-0.2\% respectively). The leucocytes superfamily is composed of many subtypes of white blood cells such as B cells and T cells usually present at $0.1-110^{6}$ cells.mL $^{-}$ ${ }^{1}$ and 1-5 $10^{6}$ cells.mL ${ }^{-1}$ respectively. The concentration variations of these cells are major data for diagnostics linked to various pathologies. To mimic such a biological sample, we used two different ${ }_{30}$ murine cell lines: LS102.9 B-type lymphocytes and 13G7 T-type lymphocytes. Each cell sample was centrifuged prior injection and the cell pellets were resuspended at $10^{6}$ cells. $\mathrm{mL}^{-1}$ in Dulbecco's Modified Eagle Medium (DMEM) supplemented with 5\% FCS. The cellular samples were then diluted in DMEM to the desired concentration prior injection. $0.3-1 \mathrm{~mL}$ were loaded into the circuit and 
moved by a pump till it arrives in the biochip reactor (Figure 1). DMEM and serum supplemented ${ }_{35}$ DMEM were used as they have a similar refractive index and also ensure cell survival during analysis. To assess the sensitivity of functionalized gold surfaces for binding of pure cell populations, three antibodies were pyrrole-modified and electro-polymerized on the biochip. Anti-mouse CD19 and CD3 monoclonal antibodies were chosen as they are directed against lymphocyte membrane proteins: the anti-CD19 antibody targets the 95-kDa CD19 glycoprotein that has been identified as a B lymphocyte${ }_{40}$ lineage antigen ${ }^{5}$ whereas the anti-CD3 antibody reacts with the $\varepsilon$-chain of the T-cell receptorassociated CD3 complex which is expressed on thymocytes, mature T lymphocytes and NK-T cells in several murine cell lines. ${ }^{6,7}$ A human immunoglobulin G (IgG) was also used as a control antibody to assay non-specific cell-binding. Biochips SPR images allowed detection of cell-surface binding (Figure 1, inset). Although lymphocytes can be considered as spheres with a $10 \mu \mathrm{m}$ diameter, they ${ }_{45}$ appeared as much larger objects on SPR images (30-50 $\mu \mathrm{m}$ diameter). This enlargement was attributed to optical limitations of our experimental setup. Indeed, due to the large biochip surface (several $\mathrm{mm}^{2}$ ) and the optical path through the prism, optical aberrations decrease the resolution and distort the objects shape depending on their position across the biochip. Even if these optical phenomena limit the study of individual cell adhesion, they do not affect the cell counting at low cell concentrations. ${ }_{50}$ Biochip bound cells could also be seen by differential interference contrast (DIC) microscopy. $\dagger$ 50 minutes after injection of LS102.9 cells (300 $\mu \mathrm{L}$ at $10^{4}$ cells.mL ${ }^{-1}$ ), 4 and 5 cells could be counted on the two anti-CD19 spots (Figure 2b) whereas 0 to 2 cells could barely be detected on four control spots. By taking into account the reactor size that is $1.5 \mathrm{~mm}$ in height, the spot diameter (c.a. $700 \mu \mathrm{m}$ ) and the cell concentration, one may estimate the number of cells suspended above each spot to about 6 ${ }_{55}$ cells. Thus, the designed biochip allowed the binding and SPR detection of approximately 3/4 of the cells present above each functionalized area. 50 minutes after injection of a 13G7 sample (300 $\mu \mathrm{L}$, $10^{4}$ cells.mL ${ }^{-1}$ ), 5 and 7 cells could be seen on the SPR images on the two anti-CD3 antibody functionalized spots but no cell was visible on control anti-CD19 spots, thus confirming the selectivity of the biochip toward another lymphocyte subtype (Figure 2c). In the case of 13G7 cells injections, we ${ }_{60}$ also observed a background cell binding to the control polyclonal IgG spots. This non-specific, reproducible interaction was seen with 13G7 cells and at a much lesser extend with LS102.9. A third cellular sample was then loaded on the biochip with a higher cell concentration (LS102.9 at $310^{4}$ cells. $\mathrm{mL}^{-1}$ ). After 50 minutes of incubation, a large number of cells could be seen on the SPR images, mainly on the anti-CD19 functionalized area but also on both the IgG and anti-CD3 spots (Figure 2d). ${ }_{65}$ This unexpected response on the anti-CD3 spots might be due to either $13 \mathrm{G} 7$ cells from the previous 
injection that were not flushed from the circuit before the LS102.9 injection, or due to biochip-bound $13 G 7$ cells that got closer to the gold surface during the LS102.9 injection, thus giving rise to a stronger SPR signal. The latter explanation was confirmed by other experiments showing slow increase of SPR signal within one hour (vide infra).

${ }_{70}$ To assess the use of our biochip for blood sample analysis, higher cell concentrations were loaded on the biochip (typically some hundreds of thousands lymphocytes per milliliter, corresponding to the amount of lymphocytes contained in more or less $100 \mu \mathrm{L}$ of blood). The SPR images recorded during these injections showed innumerable amounts of cells bound to the dedicated antibody functionalized spots thus making more challenging individual cell counting (Figure 3a). SPR images were then 75 analyzed by selecting the antibody-grafted regions and the average reflectivity variations of the chosen areas were plotted against time (Figure $3 \mathrm{~b}$ and $3 \mathrm{c}$ ). Before injection of a complex biological sample made of two different cell types, a pure B-type cell sample was loaded on the biochip to gauge a possible increase in non-specific cell binding due to high cell concentration in the biochip reactor (300 $\mu \mathrm{L}$ of LS102.9 cells at $10^{5}$ cells. $\mathrm{mL}^{-1}$ incubated for 15 minutes). After DMEM washing of the ${ }_{80}$ biochip (100 $\mu \mathrm{L} \cdot \mathrm{min}^{-1}$ for 12 minutes), only weak non-specific cell binding could be detected on both IgG control spots and T-cell spots (anti-CD3) as reflectivity increased of 0.2 and $0.3 \%$ respectively. These results, with relevant cell concentrations, strengthen the potential usage of our setup for analysis of few blood drops. Anti-CD19 grafted regions showed a much higher increase of reflectivity (more than $0.7 \%$ ) related to a spot-specific cell binding. This first injection showed that in spite of a higher ${ }_{85}$ cell concentration of the biological sample, spot-specific cell binding is still enabled. Then, a complex

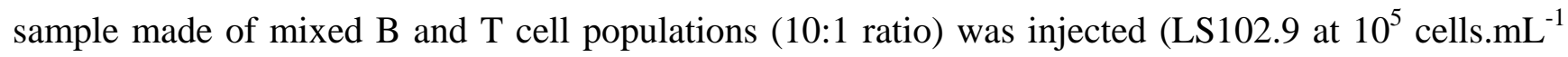
and $13 \mathrm{G} 7$ at $10^{4}$ cells.mL ${ }^{-1}$ ) at $\mathrm{t}=27$ minutes. 15 minutes after injection and washing with DMEM for 15 minutes, a small increase of reflectivity of $0.3 \%$ was measured on the control IgG spots. This variation may be due to non-specific cell binding which is consistent with the signal increase recorded ${ }_{90}$ in the previous injection. In the case of anti-CD3 and anti-CD19 antibody functionalized areas and site-specific cell binding, a significant increase of reflectivity was recorded as reflectivity signal reached $+0.5 \%$ and $+1.2 \%$ respectively after injection. This second injection of LS102.9 cells on the biochip led to a higher increase of reflectivity than the first injection at the same cell concentration $(+1.2 \%$ vs. $+0.7 \%)$. This difference might be due to slow kinetics of surface binding by the chosen cell ${ }_{95}$ populations. It means that reflectivity effects of bound cells from the first injection overlapped the reflectivity variation due to cell binding of the second injection. These results are in good qualitative agreement with the ratio of the injected cell populations. In this respect, anti-CD3 and CD19 
antibodies turned out to be the best choice among other antibodies tested during our work (data not shown).

${ }_{100}$ Higher cell concentrations of mixed populations were loaded on other biochips to appraise a possible saturation of the biochip by samples mimicking blood lymphocytes concentrations (Figure 3c). A mixture B and T cell populations (10:1 ratio) was injected (300 $\mu \mathrm{L}$ of LS102.9 at $510^{5}$ cells.mL $^{-1}$ and 13G7 at $510^{4}$ cells. $\mathrm{mL}^{-1}$ ) at $\mathrm{t}=0$ minutes. Shortly after injection, reflectivity of anti-CD3 and antiCD19 spots increased of several percents, as also IgG control spots but at a much lesser extend. After a ${ }_{105} 15$ minutes incubation, the biochip surface was washed with DMEM for 15 minutes. During this washing step, no cell was present in the reactor but the SPR signal kept increasing for both B and T cells specific regions. This variation of optical index near the surface may be due to membrane-bound antigen diffusion around the cell surface, thus locally increasing the antigen concentration and antigenantibody binding. Indeed, the diffusion coefficients measured by others for both CD3 and CD19 ${ }_{110}$ complexes across cellular membranes gave diffusion time scales in good agreement with our results obtained by SPR imaging. ${ }^{8,9}$ At $\mathrm{t}=30$ minutes, a second injection of the same mixed cell populations (10:1 ratio) was carried out (LS102.9 at $510^{5}$ cells.mL ${ }^{-1}$ and $13 G 7$ at $510^{4}$ cells.mL ${ }^{-1}$ ). This second injection led to another increase of reflectivity on the anti-CD3 and anti-CD19 areas (respectively more than $5 \%$ and $2 \%$ at $t=60$ minutes). Unlike lymphocytes specific spots, no significant reflectivity ${ }_{115}$ increase was measured on IgG spots. It is likely that the non-specific cell binding detected on the IgG grafted spots after the previous injection shielded these regions for further non-specific cell binding, thus increasing the site-specific response for the following injections. In this case, one may postulate that the cell concentrations used were high enough for saturation of non-specific binding sites. Regarding to the binding kinetics, it is also noteworthy that, once again, the reflectivity increase on the ${ }_{120} \mathrm{CD}$ spots lasted much longer than the 15 minutes incubation time. Reflectivity variations should not be considered as simple biomolecular interaction effects but rather as reflecting multiple cooperative interactions allowing binding of micrometric objects with specific viscoelastic properties. As such, affinity constants can not be extrapolated from these data. Image analysis of single cell binding, improvement of surface treatment for decreasing non-specific cell binding and broadening of this 125 method to more complex cellular samples are currently underway in our laboratory.

In summary, we have shown that SPR imaging can be used for cell-surface binding detection. It must be stressed that, using SPR imaging, only cells adhering to the surface are detected but not the cells suspended in the carrying medium. This approach is specially convenient for studying, in real time, label-free cells physically interacting on a surface (i.e. interacting within a layer of $100 \mathrm{~nm}$ above the ${ }_{130}$ Surface). The versatility of SPR cell detection opens up several fields of applications and should be 
useful in designing new miniaturized systems for diagnostic analysis (blood samples) or cell-surface adhesion kinetic studies. The authors are grateful to the Nanobio program for funding part of this work. 
${ }_{135}$ Notes and references

1 J. El-Ali, P. K. Sorger and K. F. Jensen, Nature, 2006, 442, 403-411.

2 L. Grosjean, B. Cherif, E. Mercey, A. Roget, Y. Levy, P. N. Marche, M. B. Villiers and T. Livache, Anal Biochem, 2005, 347, 193-200.

3 P. Guedon, T. Livache, F. Martin, F. Lesbre, A. Roget, G. Bidan and Y. Levy, Anal Chem, 2000, 72, 6003-6009.

$4 \quad$ K. S. Phillips and Q. Cheng, Anal Bioanal Chem, 2007, 387, 1831-1840.

$5 \quad$ T. F. Tedder and C. M. Isaacs, J Immunol, 1989, 143, 712-717.

${ }_{145} 6$ O. Leo, M. Foo, D. H. Sachs, L. E. Samelson and J. A. Bluestone, Proc Natl Acad Sci U S A, 1987, 84, 1374-1378.

7 H. Maruoka, Y. Ikarashi, K. Shinohara, M. Miyata, T. Sugimura, M. Terada and H. Wakasugi, Biochem Biophys Res Commun, 1998, 242, 413-418.

8 B. Favier, N. J. Burroughs, L. Wedderburn and S. Valitutti, Int Immunol, 2001, 13, 1525-1532.

${ }_{150} 9$ E. Balint, P. M. Grimley, Y. Gan, K. C. Zoon and A. Aszalos, Acta Microbiol Immunol Hung, 2005, 52, 407-432. 


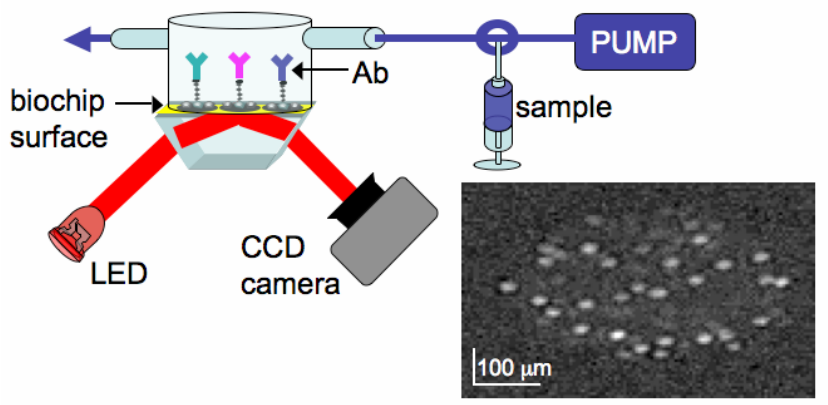

Fig.1 Schematic view of the SPR imaging setup. Inset: SPR differential image of an anti-CD19 antibody (Ab) spot 20 minutes after binding of LS102.9 cells (injection of $300 \mu \mathrm{L}$ of cells at $1.810^{5}$ cells.mL ${ }^{-1}$ ).
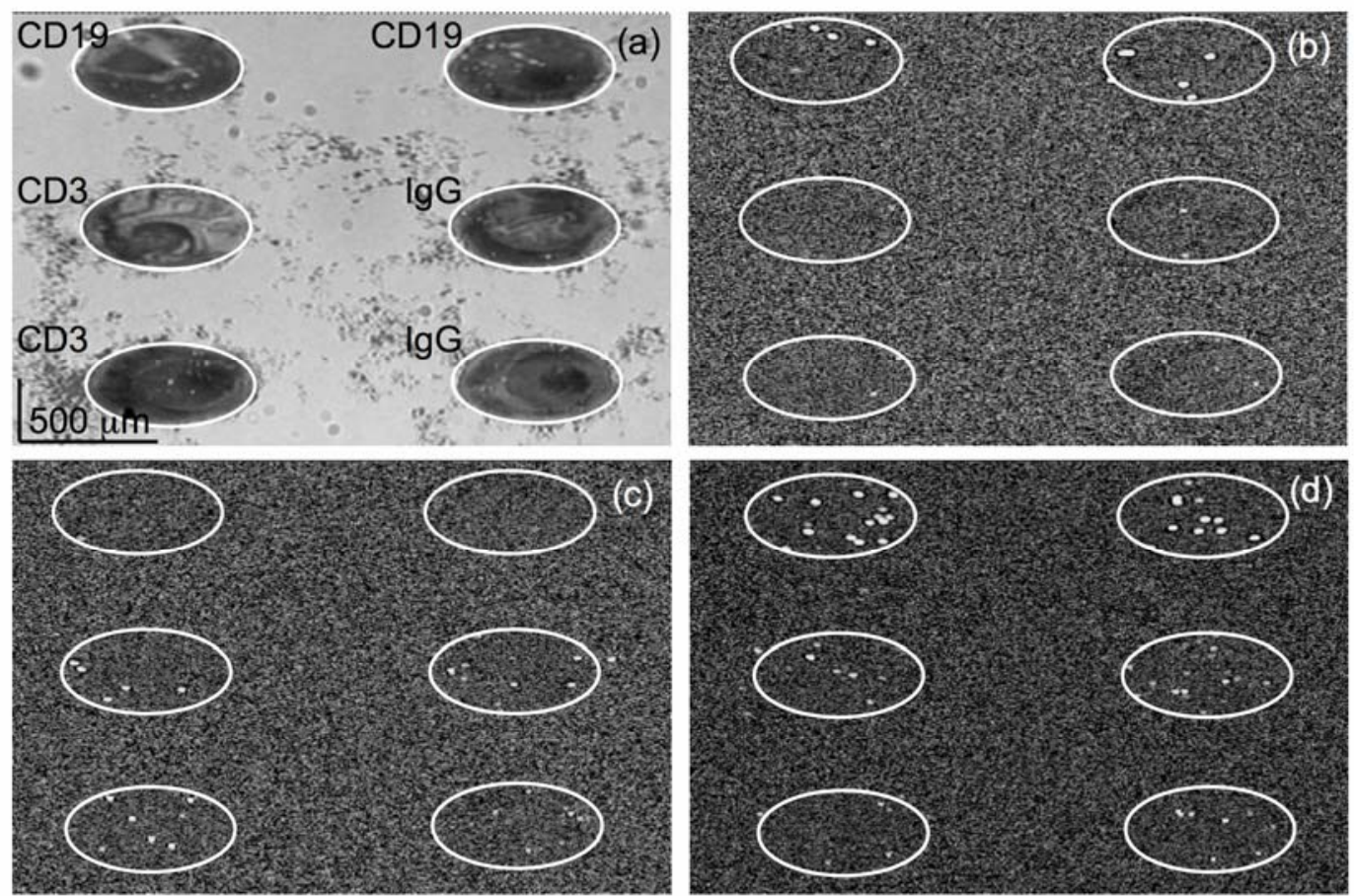

Fig.2 Cell specific binding of pure lymphocyte populations on a biochip. (a) SPR image of the surface functionalized with three different antibodies (each spotted in duplicate): anti-CD19, anti-CD3 and a control human IgG with no specific affinity for lymphocytes. (b) Differential SPR image recorded 50 minutes after a first cell injection (LS102.9 lymphocytes, $300 \mu \mathrm{L}$ at $10^{4}$ cells. $\mathrm{mL}^{-1}$ ). (c) Differential SPR image recorded 50 minutes after a second cell injection (13G7 lymphocytes, $300 \mu \mathrm{L}$ at $10^{4}$ cells.mL ${ }^{-1}$ ). (d) Differential SPR image recorded 50 minutes after a third cell injection (LS102.9 lymphocytes, $300 \mu \mathrm{L}$ at $310^{4}$ cells.mL ${ }^{-1}$ ). 

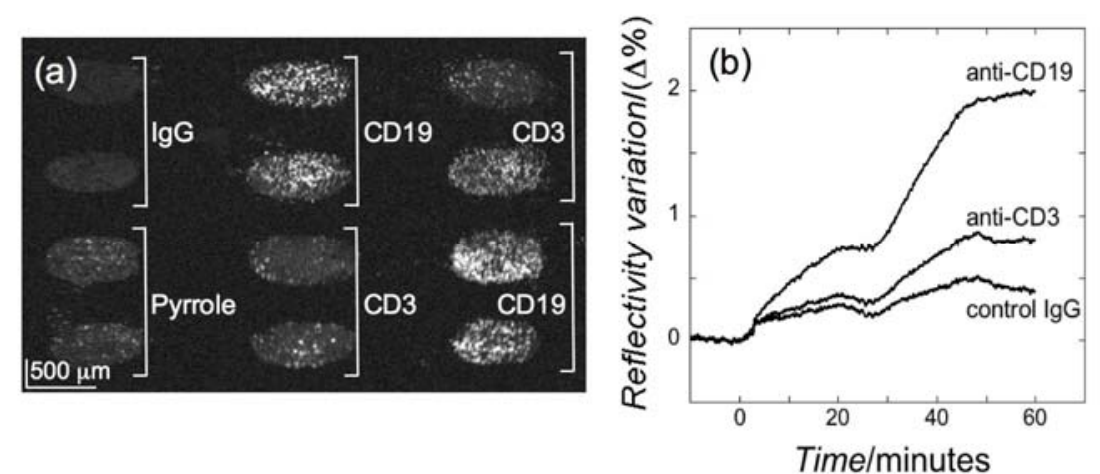

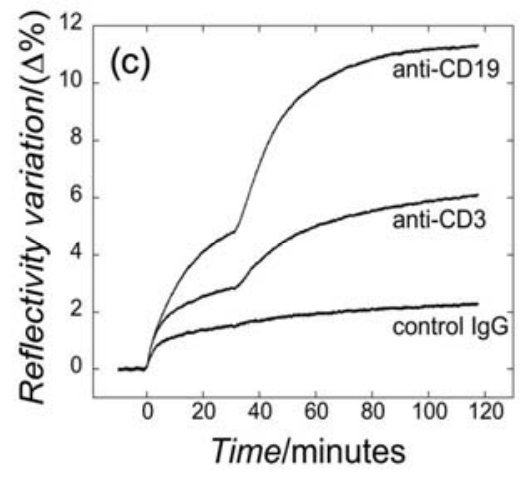

Fig.3 Reflectivity variations of the antibody functionalized areas upon cell injections on the biochip. (a) SPR differential image of the experiment described in (c) at $\mathrm{t}=70$ minutes. (b) Reflectivity variations of anti-CD3, anti-CD19 and control IgG spots after successive cell injections: LS102.9 cells $\left(300 \mu \mathrm{L}, 10^{5}\right.$ cells. $\mathrm{mL}^{-1}$ ) were injected at $\mathrm{t}=0$ minutes, the biochip was flushed with DMEM for 12 minutes at $\mathrm{t}=15$ minutes, then mixed populations of LS102.9 and 13G7 cells (300 $\mu \mathrm{L}, 10^{5}$ cells.mL ${ }^{-1}$ and $10^{4}$ cells.mL $\mathrm{mL}^{-1}$ respectively) were injected at $\mathrm{t}=27$ minutes and incubated for 15 minutes. (c) Co-

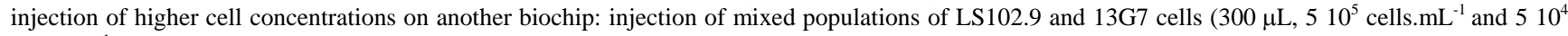
cells.mL $\mathrm{m}^{-1}$ respectively) at $\mathrm{t}=0$ minutes, the reactor was washed with DMEM for 13 minutes at $\mathrm{t}=17$ minutes, and another $300 \mu \mathrm{L}$ of the same complex sample was injected at $\mathrm{t}=30$ minutes. 